\section{Designing an Experiential Learning with Simulations and Games to Improve Education in an Undergraduate Engineering Major}

\author{
Alina Zapalska \\ U.S. Coast Guard Academy \\ alina.m.zapalska@uscga.edu
}

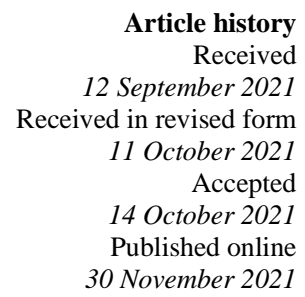

\title{
Abstract
}

This paper illustrates an experiential learning exercise that is designed to be played in an engineering undergraduate program. The author uses simulation that creates an active and experiential learning environment in which individual teams make decisions based on imperfect information and conflicting goals. The simulation allows players to control certain aspects of the information flow relevant to the market, to develop relevant business strategies and communication skills, and to establish understanding of ethical values that are relevant to business environment. The simulation was designed to allow engineering students to advance and practice business skills that are essential for engineers to stay successful in an increasingly competitive business environment. The objective is to extract maximum learning from the experience using an experiential learning model. This paper contributes to the literature on designing active learning with the use of games and simulations while utilizing the Kolb experiential learning model

Keywords: Simulation game, experiential learning, undergraduate engineering education, strategy and ethics.

\section{Introduction}

Traditional classroom, where students are passive learners and instructors transfer their knowledge on the basis of lecturing still dominates today's classroom. This teaching method has limited effectiveness in helping students develop high-level thinking skills (Miles et al., 2005). Games and simulation represent active and experiential techniques that have been used to broaden the spectrum of traditional teaching techniques and to improve the effectiveness of students' learning (Smetana, 2012). Games and simulations enable effective situated learning by simulating environments or scenarios that cannot be directly presented in a traditional classroom (Okkola and Kassi, 2012; Akilli, 2011). As experiential simulate real world situations, they promote dynamic participation and fast learning which stimulate deeper learning and comprehension of subject complexity to maximize the transfer and application of academic knowledge into specific situations (Deshpande and Huang, 2011; Mayo, 2007).

Games and simulations are experiential exercises where learners apply their knowledge and skills as well as use strategies in the execution of their assigned roles. In general, games are competitive exercises in which the objective is to win, and players apply relevant knowledge in an effort to advance in the exercise and win (Zapalska et al., 2010). In a simulation that illustrates a case study of a particular social or physical reality, the players assume roles with welldefined responsibilities and constraints. These openended situations with many interacting variables can take different directions, depending on the actions and reactions of the participants. Students' progress is monitored and assessed; feedback is given to the learners, who consider outcomes as important in their learning process. As games enable students to take decisions and manage the process, instructors are required to switch into a facilitator's role, instead of just being an observer, thus refurbishing the traditional, linear approach of content creation and delivery. Instructors act as facilitators of the experience and are responsible for ensuring that learners claim accountability for their assigned actions (Prusak, 2004). The paper demonstrates the Manufacturing Simulation that integrates the learning community with principles of communication, shared knowledge, and responsibility. The goal for engineering students is to take active roles in order to address the issues or problems that arise in the production situation and to experience the process of decision making in a business environment. The learning objective of the Manufacturing Simulation is to provide students with the opportunity to make production allocation decisions in a competitive market and to examine the strategies in which information can be used in the production allocation decision. Since no requirement is made for teams to provide or share any information, the teams may create their own business strategies and ethical system. The development of the ethical skills is also an important objective of the simulation.

The simulation involves few rounds where each of the rounds is independent and can be played relatively quickly as the market structure has been simplified. The Manufacturing Simulation as an experiential learning activity which allows engineering students to practice communication and negotiation skills as well as to develop business strategies and an understanding 
of ethics. The active learning environment allows individual teams to make decisions based on imperfect information and with conflicting goals. The simulation permits players to control certain aspects of the information flow relevant to the market, and players create their own business and ethical strategies in a complicated and uncertain business environment.

\section{Literature Review}

Games have been used to educate students for many years across all majors (Gee, 2007; Michael and Chen, 2005; Prensky, 2007). They are based on problem-based learning (Savin-Baden and Major, 2004), experiential education (Dewey, 1938/1963; Kolb, 1984), and decision science (Raser, 1969). Studies support effectiveness of simulations and games for teaching and learning (Feinstein, 2001; Hartman and Gommer, 2019). Educational research documents that simulations and games develop critical thinking, increase student motivation (Akilli, 2011), enhance team learning and collaboration, stimulate information retention (Gestwiski and Morris, 2012), improve the integration of concepts (Squire and Jenkins, 2003), and develop critical thinking and problem-solving skills (Michael, 2006). Plass (et al., 2015) argues that the use of experiential learning with games and simulations within the specific context and domain of engineering education increases motivation, student engagement, and adaptability as students benefit from their learning experiences. Frein and Ott (2015) argue that simulations in a virtual environment have been studied in various education domains when time, inaccessibility to the physical environment, safety, cost, or other barriers prevent the physical event from taking place.

Savin-Baden and Major (2004) elaborate on how gamers are successful because of development of social skills, problem solving, collaborative and teamwork skills. Similarly, Zapalska et al. (2010) claims that games improve practical reasoning skills, develop higher levels of continuing motivation, and reduce training time and instructor load. Literature (Miles, at al. 2005) highlights communication, business ethics, teamwork, leadership, and creativity. Similarly, Ellington (2001) documents that games and simulation support development of strategic thinking, planning, group decision-making as well as communication and negotiating skills. However, the relationship between learning experiences and development of business strategies such as communication and ethical standards in simulations and games still remains not fully discussed in the educational engineering education.

The simulation draws upon a rich heritage of games and simulations to demonstrate a complex interaction of production decisions as well as the role of communication and ethics within a specific business engineering environment (Gibson, 2003). Deshpande and Huang (2011) argue that simulation game-based education is the problem-based learning where both experiential learning, collaborative, active, and learner centric approaches are utilized to create an effective learning environment.

Research on games and experiential learning has proven that games and simulations are important pedagogical tools recommended for classroom use. Games and simulations reach students regardless of learning style or how quickly they are able to learn new information and concepts. Deshpande and Huang, (2011), argued that games are a method of organized experiential learning that incorporates an element of fun in the learning process while Le'ger (2006) and Williams (1980) stressed that games help connecting theory and practice to foster students' understanding of the subject as well help students to change their attitudinal positions when designed in accordance with theory. Games and simulations open up dynamic participation, develop innovative ideas and concepts (Petranek, 1994) and guide students in understanding concepts and provide students a holistic working knowledge of the subject (Kharma, 2001). Crown (2001) stressed that games and simulations deliver immediate feedback during learning process while Torres and Macedo (2000) recommended games and simulations as they provide students an opportunity to face the consequences of the results of the decisions taken or process applied. They make repetition and drill on a specific topic more enjoyable, thus allowing the student to develop proficiency in a given area. Moreover, they offer increasing range of difficulty to challenge the students as they develop to a more advanced level of comprehension (Crown, 2001) and show greater retention over time than the traditional classroom instruction (Rendal et al., 1992).

The first approach to games and simulations as an educational tool in engineering is the "Construction Management Game" (Au et al., 1969) which simulates the bidding process in the construction industry. This model has inspired a variety of research efforts in the area of games and simulations: CONSTRUCTO (Halpin and Woodhead, 1970), AROUSAL (Ndekugri and Lansley, 1992), SuperBid (AbouRizk, 1992), Parade of Trades (Choo and Tommelein, 1999), Simphony (Hajjar and AbouRizk, 1999), STRATEGY (McCabe et al., 2000), The Construction Marketing Game (Bichot, 2001), VIRCON (Jaafari et al., 2001), ER (Nassar, 2002), and the Virtual Coach (Rojas and Mukherjee, 2005). These efforts provide stepping-stones towards creating interactive, participatory, and contextually rich educational environments in construction engineering and management. Thus, using games and simulations to help students learn is not a completely new idea in the construction engineering and management education (Philpot, et al., 2003). Deshpande and Huang (2011) argue that as “... simulation games have promising applications in engineering education there is a need for a virtually integrated and comprehensive simulation game applications that will enable holistic understanding of a subject where the students can interrelate various concepts, understand the tradeoff involved, resource 
constraints, and their practical significance..." (page 408).

Keyt and Cadotte (1981) created a game that demonstrated the complex interaction of production decisions. This was a multi-period game that allowed groups to interact and introduced random factors determined by the roll of the dice. While comprehensive games have their place, it is often useful for the instructor to have an exercise that can be conducted in a single period (Brozik and Zapalska, 1997). In order to construct a single period exercise that is meaningful to the students, it is necessary to simplify the market structure and create environment that is intuitive and easy to comprehend (Cannon and Ternan, 1997). Additional benefit can be gained if an ethical dimension can be designed into the exercise (Scott, 2008; Gibson, 2003). The Manufacturing simulation, presented in this paper, was designed to meet all these requirements. Each of the rounds is independent and can be played relatively quickly because the market structure has been simplified. This market, however, can be understood by the students, and student interaction creates a unique ethical environment.

The benefits of the manufacturing simulation, presented in this paper, arrive from an active experience that students obtain while participating in this active learning. This simulation engages students in discovery processes, promotes learning through reflection on the personal learning experience, facilitates social interaction, language acquisition and communication skills as well as develops ethical aptitudes that are critical in engineering profession.

\section{Goals of Games and Simulations: teaching facts, skills, and behaviors}

The main purpose for using a simulation or game is to bring as much reality into the classroom as possible. They can be used effectively to teach concepts such as human relations, economic principles, decision-making skills, and problem solving. While it is important to consider what goes into the game, it is critical to consider what comes out of the game. Games can be used to provide three distinct outcomes: to teach facts, to teach skills, and to teach behaviors. It is also possible to have outcomes that combine one or more of these three characteristics. The desired outcome is the driving factor in the design of the game.

The Manufacturing game is fact oriented with the desired outcome for students focused on learning how businesses operate. By repeating the exercises, students can be drawn into the learning process. These types of exercises do benefit from repetition since the students that did not win the first game are provided with an incentive to study and win subsequent games. The Manufacturing game is also a skill-oriented game as it strives to teach or improve a specific, taskoriented business strategies and behavior. In this game, once the participants understand the technique and hence specific strategies that are expected to be learned, there is little use in repeating the exercise under the same initial conditions. However, modifying the boundary conditions of the game can create a new learning opportunity, but this would actually be a different game. The Manufacturing game is also a behavior-oriented game as it allows the participants to learn how to act and react in specific situations, the best example would be learning business ethics skills. The game was also used to teach participants how to communicate more effectively to accomplish desired goals. While there is possibly to advance some skill component (like business negotiation and debates) in these exercises, the overall aim of the exercise is broader than mastering a single skill.

A simulation or game may be designed to teach facts, skills, or behaviors. While each desired outcome is sufficient in itself to be the reason to design a simulation or game, combinations can be achieved to address complex issues and environments. A properly designed exercise will address only those outcomes associated with the learning goal. The Manufacturing game is an example of a fact/ skill/ behavior game/ simulation exercise that involves three primary goals. Participants need to learn the facts about the relevant manufacturing company, develop the skills and behaviors associated to business environment so that negotiation, strategic and tactical thinking skills are learned and developed. This type of simulation is fairly complex in structure and may have to be repeated to get the maximum benefit.

Moreover, The Manufacturing game has been arranged using the Kolb's experiential learning model (1984) with four major stages, including active experimentation, concrete experience, reflective observation, and abstract conceptualization. The Kolb's model is presented in Figure 1. This paper adopted the Kolb's learning process as this model views learning as an integrative process with each stage mutually supportive of and automatically leading to the next stage. This model allows students to enter the cycle at any stage and follow it through its logical sequence. Effective learning occurs when learners experience or process through all four stages of the Kolb's model.

Figure 2 presents how the model of Kolb's experiential learning has been incorporated into three rounds of experiential learning process, allowing knowledge to be continuously derived from and tested out in the experiences throughout three rounds. At each round of the Kolb's model, students discover, experience, and advance the concepts and knowledge as well as specific skills through conscious experimentation and practice. The three rounds that are implemented allow students to develop, discover, experience and advance specific skills and learn the concepts thoroughly and methodologically. This experiential learning process continues throughout three repetitive rounds allowing students to advance understanding and knowledge of specific concepts, and most importantly kills, and behaviors; including: planning, negotiation, communication, strategic 


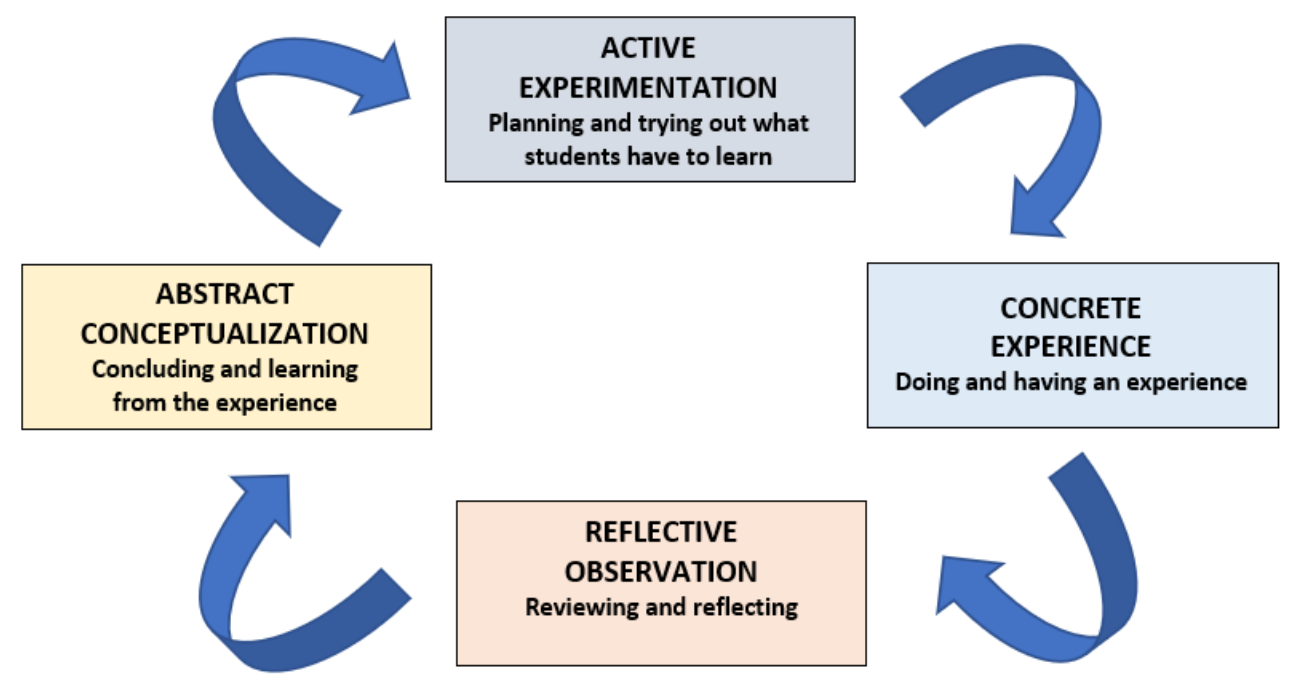

Figure 1. Kolb Model of Learning

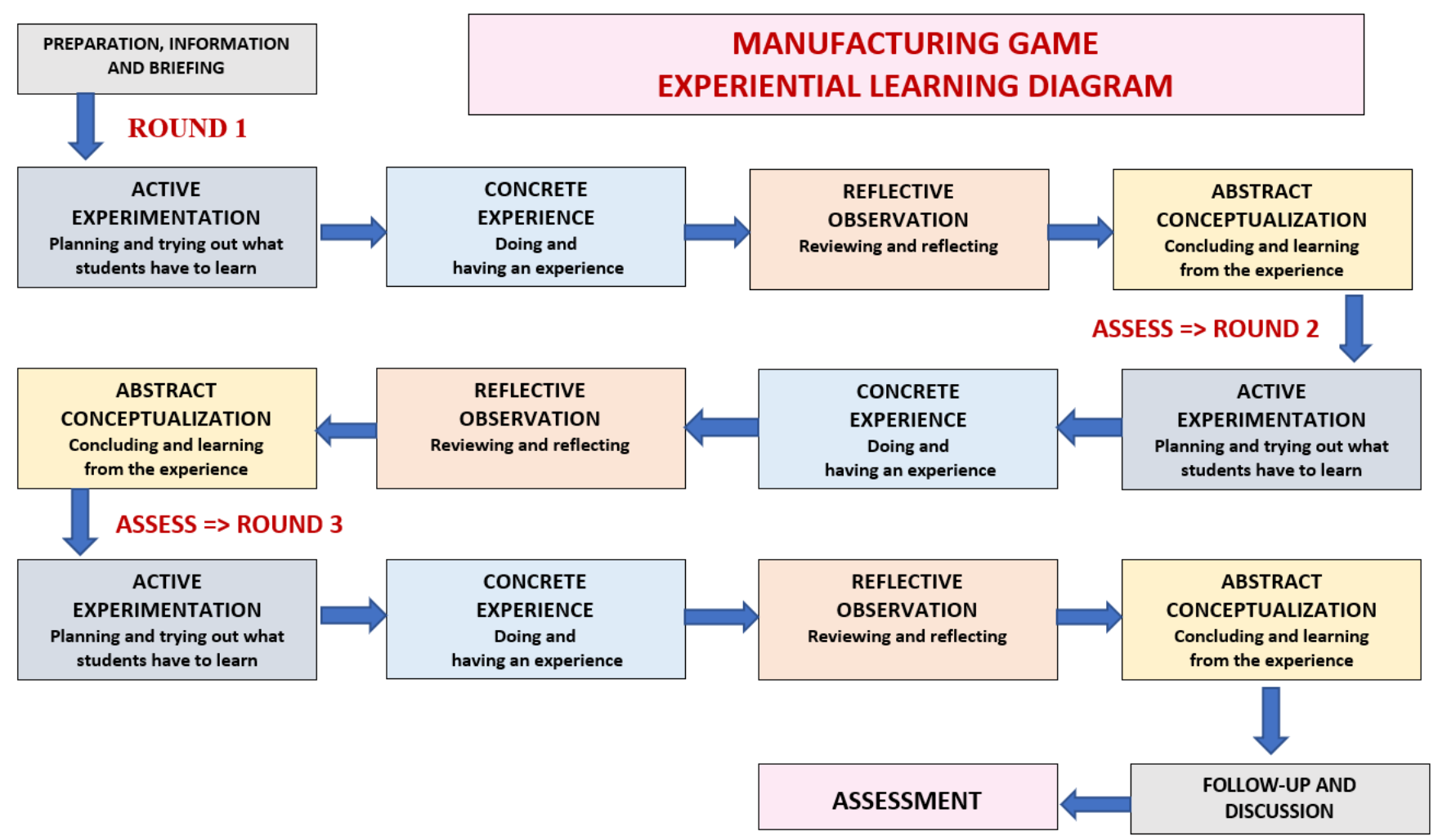

Figure 2. Experiential Learning and Manufacturing Game Diagram with Three Rounds Conducting The Manufacturing Simulation

thinking, teamwork, problem solving, and business ethics.

The Manufacturing simulation is designed to be played without computer assistance. While some instructors might choose to create spreadsheets that duplicate the Instructor's Forms, it is not necessary to do so. All required calculations can be done easily in the classroom. Each round of the simulation takes about 10 to 20 minutes. Rounds can be repeated as necessary until students demonstrate the required level of mastery. It is not necessary to complete the entire exercise in one session. The rounds are sequenced in a manner that allows the instructor to choose those that best match the class material. The periodic scheduling of the rounds may actually prove more effective in some classes since it would allow students multiple exercises to break the flow of the normal class routine and give them time to assimilate what they learn in each particular exercise.

The Manufacturing simulation is designed to be played by four teams. Team sizes can vary between three and five members. We do not recommend more than five members per team as communication is lost and inefficiencies arrive. For larger classes it is recommended that eight teams be formed and that they alternate playing the rounds. The mechanics of 
recording the results of each round can become complex when more than four teams are present. The teams should be formed at least one class session prior to playing the game by whatever protocol the instructor chooses. The simulation is composed of several rounds, each designed to illustrate a specific dimension of decision making and the information flows associated with it. The format creates a rich enough environment that factors like group dynamics and market ethics can be examined. The areas explored in each round are:

\section{Preparation, Information and Briefing Stage (Learning Objective: Facts)}

Each management team is given a Team Information Packet (Appendix A), which describes exactly how the simulation is played. This permits each team to use the time between classes to meet to discuss the facts of the game, and possibly determine an initial strategy. The Team Information Packet contains all relevant information about the simulation and Tally Sheets to facilitate score keeping. The Instructor's Forms (Appendix B) include the Master Tally Sheet and other schedules needed by the instructor. At this stage, the players are being informed that they are going to act in a competitive market. Thus, at that stage, students learn or discover facts of the game. Further, each student will act with other members of the team and represent its business firm. All teams are expected to make resource allocation decisions for their firms while competing with other firms. The teams learn that each firm has different production capacity and production costs structure. Information concerning the competition and, therefore, a market structure is incomplete and inaccurate. Moreover, knowledge of the market demand for various products is not available to the players. The teams must make decisions concerning production allocation and product mix for their firms in an uncertain environment

The Competitive Communications simulation creates a controlled, uncertain environment for decision-making. Players are formed into teams that must decide what is best for their firm, in the presence of other teams trying to do what is best for their firms. Opportunities are created for collaboration and collusion, though teams are not required to communicate any information with any other party. The interactions of the teams develop a business ethic that can also be examined.

\section{Concrete Experience - Round 1 (Doing and Having an Experience)}

After facts and foundations of the game and simulation are understood, the Concrete Experience starts with Round 1 that allows the teams to experience more than the facts. Players must understand, evaluate, analyze and solve the problem to make business decisions under market ethics. In this round, teams are experiencing decision making in isolation. All groups have the same cost structure and production capacity, so there are no inherent differences in market power. No communication is allowed between teams, and the results of the round are random. Sometimes all groups will choose to pursue a middle-of-the-road strategy, and each group gets roughly the same score. The purpose of this round is to experience and demonstrate the disadvantages of decision making without information. After teammade decisions concerning output mix without communicating with any of the other teams, they are expected to use the Tally Sheet to record their decisions. Once all teams have announced their production decisions, the sales price of each item will be calculated, and the teams can calculate the total profits earned. At this stage, students start developing communication and critical thinking skills through observation and application of several concepts they learned in class.

\section{Reflective Observation - Round 1 (Reviewing and Reflecting on the Experience)}

After the total profits are calculated, the teams reflect and evaluate their decisions regarding resource allocation and actions they took. At that stage, all teams are allowed to discuss among the group members their decisions and how their decisions affected the results. At this stage student are using analysis, evaluation, and, and problem solving, and the groups' reflection on decisions allows the groups to be prepared for Round 2 .

\section{Concrete Experience - Round 2 (Doing and Having an Experience)}

In Round 2 the groups are allowed to communicate and share information with the other teams. They can collude if they decide or do anything they wish. Given the experience gained from the Round 1, the players are ready to make decisions while using the advantages of information and use it for personal gain. No requirement is made that the information exchanged must be accurate. The players are allowed to lie if they choose as it is the beginning of the development of a market ethical system. The types of information teams decide to share, and its accuracy is up to each team. Teams, however, are under no compulsion to share information nor will there be any direct sanction for sharing inaccurate information. Teams will be required to use the Tally Sheet to record their decisions. Once all teams have announced their production decisions, the sales price of each item will be calculated, and teams will be able to calculate the total profits earned. 


\section{Reflective Observation - Round 2 (Reviewing and Reflecting on the Experience)}

After the teams calculated the profits, they are expected to reflect and evaluate their decisions regarding resource allocation in Round 2. Teams are also expected to compare their decisions in Round 2 and contrast with decisions they made in Round 1. A discussion among the group members on their decisions allows them to reflect on their decisions and how those decisions affected their results. This reflective observation prepares teams for Round 3.

\section{Concrete Experience - Round 3 (Doing and Having an Experience)}

In Round 3, production capacity, manufacturing costs, and market demand remain unchanged. In this round, an "Industry Expert" will be available to all firms for advice. During the first part of the round each firm develops a plan based upon available resources, and the Expert visits each team to review their individual strategies.

\section{Reflective Observation - Round 3 (Reviewing and Reflecting on the Experience)}

Teams are then allowed a short period of time to communicate with each other and exchange whatever information they see fit. Teams work alone to develop their final market plans. The Expert visits the teams to answer any questions concerning overall industry trends that may be beneficial in the planning process. After the Expert has visited all teams, the teams can share information with the other teams. There is no requirement that the Expert convey accurate information. There is also no requirement concerning the accuracy of the information to share. Teams experience the impact of the information accuracy on their allocation and profit results.

After teams had the opportunity to share information, the Expert will visit each team and answer questions concerning market conditions. The players will use the Tally Sheets to record their decisions. Once all teams have announced their production decisions, the sales price of each item will be calculated, and the total profits earned can be calculated.

\section{Abstract Conceptualization (Concluding and Learning from the Experience) and Active Experimentation (Planning and Trying out what was Learned)}

It is informative to foster a discussion concerning each team's decisions at each round and share their opinion of the relative honesty of the other teams and their impact on resource allocation and profits. There are definitely different opinions of exactly what happened, and it can be shown that concepts like truth and fairness can be relative or misunderstood. The cycle of experiential learn continues until facts, skills, and behaviors are learned and fully advanced. There are three rounds that allow for all those learning objectives to be completed.

\section{Follow-up and Debriefing}

After every round, students are expected to summarize their results and general debrief session is being held to make sure that the facts and certain decision-making skills are properly made. The final discussion that takes place round 3 is completed provides an overview of the problems of decision making in a dynamic environment. There should be time dedicated for a class discussion that takes place after each round concerning the success of each team and the market conditions that led to that success. Some of this discussion should focus on what information was available, the utility of this information, and the validity of the information. Discussion also should focus on the value of specific market and product characteristics, the development of the information flow, and the behavior of market participants.

\section{Assessment of the Manufacturing Simulation}

Post-simulation activity assessment can address two general purposes. One is to examine the dynamics of the simulation exercises and the overall results. The other purpose is to reinforce the process of knowledge acquisition as well as the realism of the performance feedback. Therefore, post-simulation activity is essential to fulfill the educational value of the simulation. Post-simulation activities can include postsimulation surveys, post-simulation debriefings, and group discussions. As a result of these activities, it may also be necessary for the instructor to carry out followup teaching. In order to fully realize learning effectiveness, a post-simulation survey may be administered to each individual learner immediately after the game or simulation. This survey may ask general and specific questions. General questions are usually centered in student perceptions of exercises. Specific questions tend to require learners to think analytically about their decisions and their consequences.

Assessment, evaluation, and reflection are important steps for experiential learning. Instructors can take advantage of group analyses and debriefing sessions. In these activities, learners can be asked to describe the events that occurred, account for their actions, and discuss the merits of alternative strategies to solve the problems encountered. These postsimulation activities may generate a cognitive conflict within a group of learners because students may challenge the perceptions and decisions made by others during the simulation. As a result of this cognitive conflict, learners begin to reorganize their ways of thinking about a particular set of events and how various perspectives contribute to a more complex understanding of the processes and projects 
they will work on throughout their engineering careers.

During assessment process, the instructor asks students to comment on their learning process and how this experiential learning contributed to students' learning and mastering concepts and specific skills. Some of the general comments included:

"I did enjoy this active learning as I was able to experience and make decisions to win the game. It was fun to work in teams and compete against other teams. This competition increased motivation and provided an opportunity to see how real business operates and how incentives matter."

"It was fun to play with other students while making business decision in this Manufacturing game. What I enjoyed the most was the experience, and opportunity to revised decision as the game was repetitive and allowed me to revise my decisions and improve my decision making."

"This game was very educational and even it was difficult its repetitive nature allowed me and my team to think and see how our decision making could be improved to end up with better solutions. It was also great to see how impact of other teams impacted our decisions and how difficult markets can be. My teammate and I learned that teamwork is critical in competitive environment. The game was great to play as we never do anything like this in other classes. "

\section{Conclusions}

Simulation and game-based learning approaches aim to imitate a system, entity, phenomenon, or process. They attempt to represent or predict aspects of the behavior of the problem or issue being studied. Simulation and games allow experiments to be conducted within a fictitious situation to show the real behaviors and outcomes of possible conditions. As the skills required of today's engineers are a combination of technical knowledge and management skills the Manufacturing simulation is designed to give students the opportunity to experience decision making in a dynamic setting. The firms may or may not have similar information. The information received may or may not be accurate. Expert intervention may be honest or misleading. The Manufacturing simulation shows the importance of information in decision making. Players are required to establish a market ethical system, and honesty may or may not be a part of that system. In short, the simulation allows students to experience the real world in the classroom.

Traditional education settings provide students with less opportunity for active participation and engagement due to the fear of failure. Therefore, learners need to be exposed to real-like situations in a safe place to practice various professional skills. The Manufacturing simulation presented in this paper contributes to the engineering educational literature. As a simulation-based learning environment is created, engineering students become responsible for their own learning. The role of instructor is radically different from the one in a traditional classroom environment and instructor must supervise individual work and provide help, support, and encouragement to individuals when required.

The role of instructor in our simulation is of a coach; the role of an instructor is to organize the simulation and facilitators of the learner's learning experience. The instructor has responsibility for conveying the Manufacturing simulation as a pedagogical activity. This paper has emphasized that the success of simulations as educational tools depends on the efforts performed to integrate them with other pedagogical activities. In order to enhance the effectiveness of such tools, this paper has also described activities that instructors can use before, during, and after applying games and simulations.

The Manufacturing simulation gives the instructor the ability to tailor the learning experience to classroom needs. The game can be conducted in a concentrated or extended manner, and it is only necessary to use those modules appropriate to the class. Besides the exercise in decision making and information processing, the game creates a common body of experience that is rich enough to foster discussion concerning business ethics from an experiential angle.

The Manufacturing simulation can be used in many ways and thus provides the instructor with another approach to effective learning. During simulations students learn from mistakes and thereby gain a deeper understanding of the learning objective rather than a learner who avoids mistakes by chance without understanding concepts. In addition, our simulation offers students problem solving exercises where concepts are embedded in the context promoting learning within the nexus of the activity.

\section{References}

AbouRizk, S., and Sawhney, A. (1994). Simulation and gaming in construction engineering education. ASEE/C2E2 /C2EI Conference, Edmonton, Alberta, Canada, American Society for Engineering Education.

Akilli, G. K. (2011). Games and simulations: A new approach in education. Gaming and Simulations: Concepts, Methodologies, Tools and Applications, ed. Information Resources Management Association, USA, 150-167.

$\mathrm{Au}, \mathrm{T}$., Bostleman, R. L., and Parti, E. (1969). Construction management game-deterministic model. ASCE Journal of Construction Division, 95, 25-38.

Bichot, T. (2001). The Construction Marketing Game. Masters Thesis, Bradley University, Peoria, Illinois.

Brozik and Zapalska (1997) "The Market Game: Interactive Learning Through Market Simulation." Developments in Business Simulation and Experiential Learning, Volume 24, 1997, 166-171.

Choo, H. J., and Tommelein, I. D. (1999). Parade of trades: A computer game for understanding variability and dependence. Technical Report 99-1, Construction Engineering and Management Program, Civil and Environmental Engineering Department, University of California, Berkeley, CA, September. 
Cannon and Ternan (1997) "Contextually-Anchored Business Simulations." Developments in Business Simulation and Experiential Learning, Volume 24, 1997, 322-328.

Crown, S. W. (2001). Improving visualization skills of engineering graphics students using simple JavaScript web-based games, Journal of Engineering Education. 90), 347-355.

Dewey, J. (1938/1963). Experience and Education. New York: Collier Books.

Deshpande, A. A., and Huang, S. H. (2011). Simulation games in engineering education: A state-of-the-art review. Computer Applications in Engineering Education, 19(3), 399-410.

Ellington, H. (2001) 'Using Games Simulations and Case Studies to Develop Key Skills', in M. Boyle and Y. Smith (eds) Simulation and Gaming Research Yearbook, SAGSET.

Feinstein, A. H. (2001) 'An Assessment of the Effectiveness of Simulation as an Instructional System', Journal of Hospitality and Tourism Research 25(4): 421-43.

Frein, L., \& Ott, M. (2015). A literature review on immersive virtual reality in education: State of the art and perspectives. eLearning and Software for Education (eLSE), April 23-24, Bucharest, Romania.

Gee, J. P. (2007). What Video Games Have to Teach Us About Learning and Literacy, New York: Palgrave MacMillan.

Gibson, K. (2003). Games students play: Incorporating the prisoner's dilemma in teaching business ethics. Journal of Business Ethics, 48(1), 53-64.

Gestwicki, P., \& Morris, R. (2012). Social Studies Education Game Development as an Undergraduate Immersive Learning Experience. In M. Cruz-Cunha (Ed.), Handbook of Research on Serious Games as Educational, Business and Research Tools (pp. 838-858). Hershey, PA: Information Science Reference. doi:10.4018/978-1-4666-0149-9.ch043

Hajjar, D., and AbouRizk, S. (1999). Simphony: An environment for building special purpose construction simulation tools. Proceedings of the 1999 Winter Simulation Conference, December, 998-1006.

Halpin, D.W., and Woodhead, R.W. (1970). CONSTRUCTO - A computerized construction management game. Construction Research Series, No.14, Department of Civil Engineering, University of Illinois, Urbana, IL, December.

Hartmann, A., Gommer, L.: To play or not to play: on the motivational effects of games in engineering education. European Journal of Engineering Education. (2019)

Jaafari, A., Manivong, K., and Chaaya, M. (2001). VIRCON: Interactive system for teaching construction management. Journal of Construction Engineering and Management, 127(1), 66-75.

Keyt and Cadotte (1981) "CHIPS: A Marketing Channels Management Game." Developments in Business Simulation and Experiential Learning, Volume 8, 1981, 242-246.

Kharma, N. L. Caro, and V. Venkatesh, (2001). MagicBlocks: A construction kit for learning digital logic, Computer Application Engineering Education. 13, 35-46.

Kolb, D. A. (1984). Experiential Learning: Experience as the Source of Learning and Development. Englewood. Cliffs: Prentice-Hall.

Le'ger. P.M. (2006). Using a simulation game approach to teach ERP concepts, HEC Montre'al, Groupe de recherche en syste'mes d'information, Montre'al.

Mayo, M. J. (2007). Games for Science and Engineering Education. Communications of the ACM, 50(7), 31-35.

McCabe, B. Y., Ching, K. S., \& Savio, R. (2000). STRATEGY: A Construction simulation environment. Proceedings of the ASCE Construction Congress VI, Orlando, FL, February, $115-120$

Michael, J. (2006). Where's the evidence that active learning works? Advances in Physiology Education, 30(4), 159167.
Michael, D., and Chen, S. (2005). Serious Games: Games That Educate, Train, and Inform, Boston: Thomson Course Technology PTR.

Miles, M., Melton, D., Ridges, M. and Harrell, C. (2005), "The Benefits of Experiential Learning in Manufacturing Education", Journal of Engineering Technology, Vol. 22, No. 1, pp. 24-28.

Nassar, K. (2002). Simulation gaming in construction: ER, the equipment replacement game. Journal of Construction Education. 7(1), 16-30.

Ndekugri, I. Y., and Lansley, P. (1992). Role of simulation in construction management. Building Research and Information, 20 (2), 109-115.

Okkola, T. and Kässi, T. (2012), "Designing an Industrial Management Curriculum, Overcoming Obstacles", Int. Journal of Industrial Engineering and Management, Vol. 3, No. 2, pp. 67-74.

Petranek, C. (1994). Amaturation in experiential learning: Principles of simulation and gaming, Simulat Gaming: International Journal. 25, 513-522.

Philpot, T. A., Hubing, N., Hall, R. H., Flori, R. E., Oglesby, D. B., \& Yellamraju, V. (2003). Games as teaching tools in engineering mechanics courses. In Proceedings of the American Society of Engineering Education.

Plass, J., Homer, B., Kinzer, C. (2015). Foundations of gamebased learning. Educational Psychology. 50(4), 258-283

Prensky, M. (2007). Digital Game-Based Learning. St. Paul, Minnesota: Paragon House Publishers.

Prusak, K. (2004), "Problem Definition and Problem Solving in Lean Manufacturing Environment", in Proceedings of the 2004 American Society for Engineering Education Annual Conference \& Exposition, pp. 195-206.

Randel, J. M., B. A. Morris, C. D. Wetzel, and B. V. Whitehill. (1992). The effectiveness of games for educational purposes: A review of recent research, Simulation Gaming 23, 261-276.

Raser, J. R. (1969). Simulation and Society: An Exploration of Scientific Gaming. Boston: Allyn and Bacon Inc.

Rojas, E., and Mukherjee, A. (2005). A general-purpose situational simulation environment for construction education. Journal of Construction Engineering and Management, ASCE, 131 (3), 319-329.

Savin-Baden, M., and Major, C. H. (2004). Foundations of Problem-Based Learning, Maidenhead: The Society for Research into Higher Learning \& Open University Press.

Scott, J.A. (2008). Simulations as a Source of Learning: Using StarPower to teach Ethical Leadership and Management. Journal of Leadership Education. 7 (1).140-149.

Smetana, L. K., and Bell, R. L. (2012). Computer simulations to support science instruction and learning: A critical review of the literature. International Journal of Science Education, 34(9), 1337-1370.

Squire, K., \& Jenkins, H. (2003). Harnessing the power of games in education. Insight, 3(1), 5-33.

Thavikulwat (1988) "Simulating Demand in an IndependentAcross-Firms Management Game." Developments in Business Simulation and Experiential Learning, Volume 15, 1988, 183-187.

Torres, M. and J. Macedo, (2000). Learning sustainable development with a new simulation game, Simulation Gaming. 31, 119-126.

Williams, R. H. (1980). Attitude change and simulation games: The ability of a simulation game to change attitudes when structured in accordance with either the cognitive dissonance or incentive models of attitude change, Simulation Games, 11, 177-196.

Zapalska, A., Brozik, D., and D. Rudd. (2010). "Development of Active Learning with Simulations and Games". US-China Education Review, A 2, 164-169. 


\section{APPENDIX A:}

\section{TEAM INFORMATION PACKET}

\section{COMPETITIVE MARKETS AND COMMUNICATIONS}

\section{THE SCENARIO:}

Your firm is one of several international manufacturers of electrical generation and transmission equipment. Due to the recent power shortages in the United States and other parts of the world, there has been an increased demand for the products you manufacture. As managers of your firm, it is your responsibility to plan production and sales to meet the demands of a competitive market in order to maximize the wealth of your shareholders.

\section{THE COMPETITION:}

You have three major competitors that are roughly the same size and that produce equipment with the same capabilities as your firm's products. These four firms form an industry subgroup:

$$
\begin{gathered}
\text { Northern Wind Energy } \\
\text { Eastern Solar Equipment } \\
\text { Southern Hydrodynamics Systems } \\
\text { Western Hybrid Components }
\end{gathered}
$$

These firms compete directly on the following items:

$$
\text { Frequency Modulators (FM) }
$$

Voltage Transformers (VT)

Power Regulators (PR)

From the point of view of potential customers, your firm's products are interchangeable with those of any of your competitors. For example, a frequency modulator from any of the four firms is considered to be identical in capability. (Note: A frequency modulator is not interchangeable with a voltage transformer or power regulator.)

\section{DOMICILE:}

None of the four firms is based in the United States even though the US is a major market for these products. Since the firms are not bound by US laws, there is no legal restriction (anti-trust laws) against sharing information between firms, but there is likewise no requirement that information be shared. The amount of information exchanged between firms is decided by the managers of the firm, as is the accuracy of that information. Even though these firms are based in different countries, since their products are sold in the US, all cost and price information is quoted in US dollars.

\section{THE DECISION REQUIREMENT:}

In each round of the game, you will be required to decide how many of each type of product to sell in order to maximize the wealth of your individual shareholders. There are two specific production factors that you must consider in making your product allocation.

1. The quantity of each item you plan to produce must be a multiple of ten. For example, if you have 100 items to allocate, you can choose to produce $10 \mathrm{FM}, 20 \mathrm{VT}$, and $70 \mathrm{PR}$ or any other combination that adds to 100 units as long as each individual allocation is a multiple of ten. You cannot choose to produce 3 FM, 5 VT, and 92 PR. Should you choose to allocate production quantities that are not multiples of ten, the number that you choose will be rounded down to the nearest multiple of ten; this will result in your team losing production and thus losing revenues.

2. In order to maintain the ability to offer a product in the next round, you must offer at least 10 of that product in the preceding round. This requirement assures that the equipment and personnel needed for production will be available. For example, if in Round 1 you choose not to produce any FM, then you will not be allowed to offer any FM in Round 2. You will be allowed to offer FM in Round 3 should you wish to do so. The reason that you must skip a round after not offering a product is that it will take you this much time to restart the production process.

\section{THE GAME STRUCTURE:}

There are multiple rounds to the game, each round examining a different aspect of competition and information flow. Cost and price structures may change between rounds, and it is your responsibility to make decisions in light of the changing market conditions. During each round, you will have approximately 10 minutes to decide your production mix.

\section{MANAGERIAL INCENTIVES:}

In order to receive credit for this part of the course, you will be required to submit a paper documenting the game and your performance during the game. This paper will be graded on a 100-point scale. The members of the winning team in each round of the game will receive a 5-point bonus which will be added to the grade on the paper. For example, if a single team is able to win three rounds, it would be possible for the members of that team to receive a score of 115 points 
on the 100-point paper (if the paper itself does not merit a score of 100 , the bonus points will still be added to whatever score the paper receives). In each round, the members of the second-place team will receive a bonus of 3 points, and the members of the third-place team will receive a bonus of 1 point.

In the event of a two-way tie in any round, the combined points will be split equally between the two tying teams. If the tie involves more than two teams, that is, if three or more teams receive the same score in a specific round, no bonus points will be awarded to those teams for that round.

\section{COMPETITIVE MARKETS PRODUCT DEMAND CURVES}

An industry marketing board has surveyed potential buyers of electrical equipment. Based on the information from this survey, the following demand schedules have been constructed for the products your firm manufactures. Due to market conditions, the minimum price for any product is $\$ 100,000$ regardless of the quantity available in the market.

\section{COMPETITIVE MARKETS AND COMMUNICATIONS}

Manufacturing Capacity: Each firm has the capacity to produce a total of 150 units. Due to the manufacturing process, it takes the same amount of time and materials for each product. The firm can therefore produce various combinations of finished products, like $150 \mathrm{FM}$ and $0 \mathrm{VT}$ and $0 \mathrm{PR}$, or $50 \mathrm{FM}$ and $50 \mathrm{VT}$ and $50 \mathrm{PR}$, or any other combination that totals 150 units.

Manufacturing Costs: The cost to produce a single unit (FM, VT, or PR) is $\$ 300,000$.

Product Demand: See Product Demand Curve graphs.

\section{ROUND 1}

Make your decision concerning your output mix without communicating with any of the other teams. Use the Tally Sheet o record your decision. Once all teams have announced their production decisions, the sales price of each item will be calculated, and you can calculate the total profits earned.

\section{ROUND 2}

Prior to making the output mix decision, you may share information with the other teams. The type of information you share, and its accuracy, is up to you. You are under no compulsion to share information, nor will there be any direct sanction for sharing inaccurate information. Use the Tally Sheet to record your decision. Once all teams have announced their production decisions, the sales price of each item will be calculated, and you can calculate the total profits earned.

\section{ROUND 3}

An Industry Expert will be available to assist you should you wish. While you are making your initial plans, the Expert will visit your team and ask questions. It is your choice whether or not the information you provide is accurate. After the Expert has visited all teams, the teams can share information with the other teams. There is no requirement concerning the accuracy of the information you share. After you have had the opportunity to share information, the Expert will visit each team and answer questions concerning market conditions. Use the Tally Sheet to record your decision. Once all teams have announced their production decisions, the sales price of each item will be calculated, and you can calculate the total profits earned.
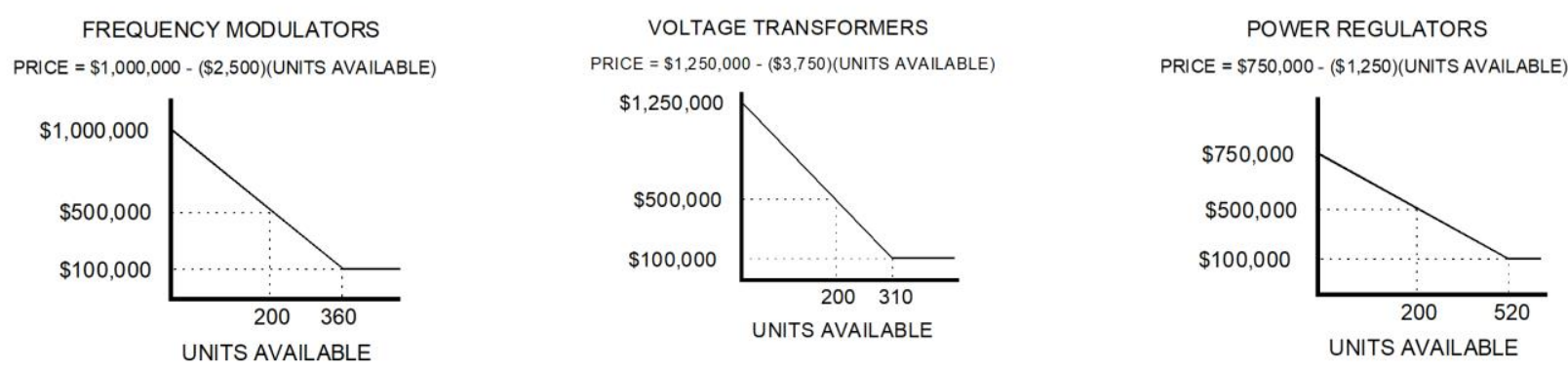
APPENDIX B: INSTRUCTOR'S FORMS

PRODUCTION ALLOCATION
\begin{tabular}{|l|c|c|c|c|}
\multicolumn{1}{|c|}{ ROUND 1 } \\
\cline { 2 - 5 } & FM & VT & PR & Total units \\
\hline North & & & & 150 \\
\hline East & & & & 150 \\
\hline South & & & & 150 \\
\hline West & & & & 150 \\
\hline \multicolumn{1}{|c|}{ Total } & & & & \\
\hline
\end{tabular}

\begin{tabular}{|l|c|c|c|c|}
\multicolumn{1}{|c|}{} & FM & VT & PR & Total units \\
\hline North & & & & 150 \\
\hline East & & & & 150 \\
\hline South & & & & 150 \\
\hline West & & & & 150 \\
\hline \multicolumn{1}{|c|}{ Total } & & & & \\
\hline
\end{tabular}

\begin{tabular}{|l|c|c|c|c|}
\hline \multicolumn{1}{|c|}{ ROUND 3 } \\
\cline { 2 - 5 } & FM & VT & PR & Total units \\
\hline North & & & & 150 \\
\hline East & & & & 150 \\
\hline South & & & & 150 \\
\hline West & & & & 150 \\
\hline \multicolumn{1}{|c|}{ Total } & & & & \\
\hline
\end{tabular}

\begin{tabular}{|c|c|c|c|c|c|}
\hline \multicolumn{6}{|c|}{ ROUND 1} \\
\hline & & FM & vT & PR & \\
\hline \multirow[t]{5}{*}{ North } & \# UNITS & & & & \\
\hline & PRICE/UNIT & & & & \\
\hline & COST/UNIT & $\$ 300,000$ & $\$ 300,000$ & $\$ 300,000$ & \\
\hline & PROFIT/UNIT & & & & TOTAL PROFIT \\
\hline & PROFIT & & & & \\
\hline \multirow[t]{5}{*}{ East } & \# UNITS & & & & \\
\hline & PRICE/UNIT & & & & \\
\hline & COST/UNIT & $\$ 30,000$ & $\$ 300,000$ & $\$ 300,000$ & \\
\hline & PROFIT/UNIT & & & & TOTAL PROFIT \\
\hline & PROFIT & & & & \\
\hline \multirow[t]{5}{*}{ South } & \# UNITS & & & & \\
\hline & PRICE/UNIT & & & & \\
\hline & COST/UNIT & $\$ 300,000$ & $\$ 300,000$ & $\$ 300,000$ & \\
\hline & PROFIT/UNIT & & & & TOTAL PROFIT \\
\hline & PROFIT & & & & \\
\hline \multirow[t]{5}{*}{ West } & \# UNITS & & & & \\
\hline & PRICE/UNIT & & & & \\
\hline & COST/UNIT & $\$ 300,000$ & $\$ 300,000$ & $\$ 300,000$ & \\
\hline & PROFIT/UNIT & & & & TOTAL PROFIT \\
\hline & PROFIT & & & & \\
\hline
\end{tabular}

\begin{tabular}{|c|c|c|c|c|c|}
\hline \multicolumn{6}{|c|}{ ROUND 2} \\
\hline & & FM & VT & PR & \\
\hline \multirow[t]{5}{*}{ North } & \# UNITS & & & & \\
\hline & PRICE/UNIT & & & & \\
\hline & COST/UNIT & $\$ 300,000$ & $\$ 300,000$ & $\$ 300,000$ & \\
\hline & PROFIT/UNIT & & & & TOTAL PROFIT \\
\hline & PROFIT & & & & \\
\hline \multirow[t]{5}{*}{ East } & \# UNITS & & & & \\
\hline & PRICE/UNIT & & & & \\
\hline & COST/UNIT & $\$ 300,000$ & $\$ 300,000$ & $\$ 300,000$ & \\
\hline & PROFIT/UNIT & & & & TOTAL PROFIT \\
\hline & PROFIT & & & & \\
\hline \multirow[t]{5}{*}{ South } & \# UNITS & & & & \\
\hline & PRICE/UNIT & & & & \\
\hline & COST/UNIT & $\$ 300,000$ & $\$ 300,000$ & $\$ 300,000$ & \\
\hline & PROFIT/UNIT & & & & TOTAL PROFIT \\
\hline & PROFIT & & & & \\
\hline \multirow[t]{5}{*}{ West } & \# UNITS & & & & \\
\hline & PRICE/UNIT & & & & \\
\hline & COST/UNIT & $\$ 300,000$ & $\$ 300,000$ & $\$ 300,000$ & \\
\hline & PROFIT/UNIT & & & & TOTAL PROFIT \\
\hline & PROFIT & & & & \\
\hline
\end{tabular}

Team Name/Members:

\begin{tabular}{|l|c|c|c|c|}
\hline \multicolumn{2}{|c|}{ Product } & FM & VT & PR \\
\hline Sales Price per Unit & & & \\
\hline Cost per Unit & $\$ 300,000$ & $\$ 300,000$ & $\$ 300,000$ & \multirow{2}{*}{ Total Units Sold } \\
\hline Profit per Unit & & & & 150 \\
\hline Units Sold & & & & \\
\hline Total Profit per Product & & & & Grand Total Profit \\
\hline
\end{tabular}

\begin{tabular}{|l|c|c|c|c|}
\hline \multicolumn{1}{|c|}{ Product } & FM & VT & PR & \\
\hline Sales Price per Unit & & & & \\
\hline Cost per Unit & $\$ 300,000$ & $\$ 300,000$ & $\$ 300,000$ & \multirow{2}{*}{ Total Units Sold } \\
\hline Profit per Unit & & & & 150 \\
\hline Units Sold & & & & \\
\hline Total Profit per Product & & & & \multicolumn{2}{|c|}{ Grand Total Profit } \\
\hline
\end{tabular}

\begin{tabular}{|l|c|c|c|c|}
\multicolumn{2}{|c|}{ ROUND 3 } \\
\cline { 2 - 4 } Product & FM & VT & PR & \\
\hline Sales Price per Unit & & & & \multirow{2}{*}{ Total Units Sold } \\
\hline Cost per Unit & $\$ 300,000$ & $\$ 300,000$ & $\$ 300,000$ & \\
\hline Profit per Unit & & & & \\
\hline Units Sold & & & & \multicolumn{2}{|c|}{ Grand Total Profit } \\
\hline Total Profit per Product & & & & \\
\hline
\end{tabular}




\begin{tabular}{|c|c|c|c|c|c|}
\hline \multicolumn{6}{|c|}{ ROUND 3} \\
\hline & & FM & VT & PR & \\
\hline \multirow[t]{5}{*}{ North } & \# UNITS & & & & \\
\hline & PRICE/UNIT & & & & \\
\hline & COST/UNIT & $\$ 300,000$ & $\$ 300,000$ & $\$ 300,000$ & \\
\hline & PROFIT/UNIT & & & & TOTAL PROFIT \\
\hline & PROFIT & & & & \\
\hline \multirow[t]{5}{*}{ East } & \# UNITS & & & & \\
\hline & PRICE/UNIT & & & & \\
\hline & COST/UNIT & $\$ 300,000$ & $\$ 300,000$ & $\$ 300,000$ & \\
\hline & PROFIT/UNIT & & & & TOTAL PROFIT \\
\hline & PROFIT & & & & \\
\hline \multirow[t]{5}{*}{ South } & \# UNITS & & & & \\
\hline & PRICE/UNIT & & & & \\
\hline & COST/UNIT & $\$ 300,000$ & $\$ 300,000$ & $\$ 300,000$ & \\
\hline & PROFIT/UNIT & & & & TOTAL PROFIT \\
\hline & PROFIT & & & & \\
\hline \multirow[t]{5}{*}{ West } & \# UNITS & & & & \\
\hline & PRICE/UNIT & & & & \\
\hline & COST/UNIT & $\$ 300,000$ & $\$ 300,000$ & $\$ 300,000$ & \\
\hline & PROFIT/UNIT & & & & TOTAL PROFIT \\
\hline & PROFIT & & & & \\
\hline
\end{tabular}

\begin{tabular}{|c|c|c|c|}
\hline \multicolumn{4}{|c|}{ UNIT PRICES } \\
\hline \# UNITS & VT & FM & PR \\
\hline 0 & $1,250,000$ & $1,000,000$ & 750,000 \\
\hline 10 & $1,212,500$ & 975,000 & 737,500 \\
\hline 20 & $1,175,000$ & 950,000 & 725,000 \\
\hline 30 & $1,137,500$ & 925,000 & 712,500 \\
\hline 40 & $1,100,000$ & 900,000 & 700,000 \\
\hline 50 & $1,062,500$ & 875,000 & 687,500 \\
\hline 60 & $1,025,000$ & 850,000 & 675,000 \\
\hline 70 & 987,500 & 825,000 & 662,500 \\
\hline 80 & 950,000 & 800,000 & 650,000 \\
\hline 90 & 912,500 & 775,000 & 637,500 \\
\hline 100 & 875,000 & 750,000 & 625,000 \\
\hline 110 & 837,500 & 725,000 & 612,500 \\
\hline 120 & 800,000 & 700,000 & 600,000 \\
\hline 130 & 762,500 & 675,000 & 587,500 \\
\hline 140 & 725,000 & 650,000 & 575,000 \\
\hline 150 & 687,500 & 625,000 & 562,500 \\
\hline 160 & 650,000 & 600,000 & 550,000 \\
\hline 170 & 612,500 & 575,000 & 537,500 \\
\hline 180 & 575,000 & 550,000 & 525,000 \\
\hline 190 & 537,500 & 525,000 & 512,500 \\
\hline 200 & 500,000 & 500,000 & 500,000 \\
\hline 210 & 462,500 & 475,000 & 487,500 \\
\hline 220 & 425,000 & 450,000 & 475,000 \\
\hline 230 & 387,500 & 425,000 & 462,500 \\
\hline 240 & 350,000 & 400,000 & 450,000 \\
\hline 250 & 312,500 & 375,000 & 437,500 \\
\hline 260 & 275,000 & 350,000 & 425,000 \\
\hline 270 & 237,500 & 325,000 & 412,500 \\
\hline 280 & 200,000 & 300,000 & 400,000 \\
\hline 290 & 162,500 & 275,000 & 387,500 \\
\hline 300 & 125,000 & 250,000 & 375,000 \\
\hline 310 & 100,000 & 225,000 & 362,500 \\
\hline 320 & 100,000 & 200,000 & 350,000 \\
\hline 330 & 100,000 & 175,000 & 337,500 \\
\hline 340 & 100,000 & 150,000 & 325,000 \\
\hline 350 & 100,000 & 125,000 & 312,500 \\
\hline 360 & 100,000 & 100,000 & 300,000 \\
\hline 370 & 100,000 & 100,000 & 287,500 \\
\hline 380 & 100,000 & 100,000 & 275,000 \\
\hline 390 & 100,000 & 100,000 & 262,500 \\
\hline 400 & 100,000 & 100,000 & 250,000 \\
\hline
\end{tabular}

